\title{
Solar radiation trend across China in recent decades: a revisit with quality-controlled data
}

\author{
W.-J. Tang ${ }^{1,2}$, K. Yang ${ }^{1}$, J. Qin ${ }^{1}$, C. C. K. Cheng ${ }^{3}$, and J. He ${ }^{1,2}$ \\ ${ }^{1}$ Key Laboratory of Tibetan Environment Changes and Land Surface Processes, Institute of Tibetan Plateau Research, \\ Chinese Academy of Sciences, Beijing 100085, China \\ ${ }^{2}$ Graduate School of Chinese Academy of Sciences, Beijing 100049, China \\ ${ }^{3}$ Department of Building and Construction, City University of Hong Kong, Tat Chee Avenue, Kowloon, Hong Kong, China
}

Received: 24 June 2010 - Published in Atmos. Chem. Phys. Discuss.: 3 August 2010

Revised: 21 November 2010 - Accepted: 17 December 2010 - Published: 14 January 2011

\begin{abstract}
Solar radiation is one of the most important factors affecting climate and environment, and its long-term variation is of much concern in climate change studies. In the light of the limited number of radiation stations with reliable longterm time series observations, this paper presents a new evaluation of the long-term variation of surface solar radiation over China by combining quality-controlled observed data and two radiation models. One is the ANN-based (Artificial Neutral Network) model and the other is a physical model. The two models produce radiation trends comparable to the observed ones at a few validation stations possessing reliable and continuous data. Then, the trend estimate is extended by the ANN-based model to all 96 radiation stations and furthermore extended by the physical model to all 716 China Meteorological Administration (CMA) routine stations. The new trend estimate is different from previous ones in two aspects. First, the magnitude of solar radiation over China decreased by about $-0.23 \mathrm{~W} \mathrm{~m}^{-2} \mathrm{yr}^{-1}$ between 1961 and 2000, which is greatly less in magnitude than trend slopes estimated in previous studies (ranging over $-0.41 \sim-0.52 \mathrm{~W} \mathrm{~m}^{-2} \mathrm{yr}^{-1}$ ). Second, the "From Dimming to Brightening" transition in China during the late 1980s the early 1990s was addressed in previous studies, but this study indicates the solar radiation reached a stable level since the 1990s and the transition is not noticeable. These differences indicate the importance of data-quality control and analysis approaches. Finally, an obvious transition from brightening to dimming around 1978 is found over the Tibetan Plateau, where aerosol loads are very low, indicating that the importance of cloud changes in altering solar radiation may be comparable to that of the aerosol changes.
\end{abstract}

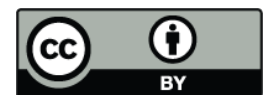

Correspondence to: $\mathrm{K}$. Yang (yangk@itpcas.ac.cn)

\section{Introduction}

As the ultimate energy source for the lives on our planet, solar radiation incident at the Earth's surface drives most of the water, energy, and carbon cycles of the Earth's system, and it is also a major determinant of the climate conditions of our habitats (Wild et al., 2009b). Changes in the amount of solar radiation have received prominent attention due to its potential influences on the environmental, societal, and economic aspects of people's living (Pinker et al., 2005). These changes could be the consequences from either or both natural and anthropogenic factors such as large amount of emission by volcanic eruption, emission of pollutants from industrial or commercial activities, and climatic change. Measurement of solar radiation is of primary importance because it provides the most essential information for evaluation of climate changes and global warming due to its high sensitivity to the anthropogenic disturbances (Ramanathan et al., 2001). Long-term variations in the observed records of surface solar radiation have been widely investigated in many countries (Stanhill et al., 1995, 1997, 1998; Abakumova et al., 1996; Liepert et al., 1997, 2002; Wild et al., 2009a, 2009b; Gilgen et al., 1998, 2009). They found that the intensity of solar radiation incident on the Earth's surface has a decreasing trend (about 6 to $9 \mathrm{~W} \mathrm{~m}^{-2}$ from the 1960 s to the 1990 s, i.e. about $5 \%$ ). This decreasing trend is believed to have a profound impact on the climate, hydrological cycle, plant photosynthesis, solar power intensity, and daylighting availability. However, Wild et al. (2005) found that the decreasing trend does not persist into the 1990s and they reported that there is a recovery trend since the late 1980s in most regions of the world. This result well agrees with satellite observation on the land surface of the Earth (Pinker et al., 2005). This transition phenomenon is popularly called "From Dimming to Brightening".

Published by Copernicus Publications on behalf of the European Geosciences Union. 
There are also many similar studies which have been done to investigate the long-term variations of surface solar radiation over China. A preliminary study of the solar radiation data collected at three observation stations in the Yangtze River Delta Region was done by Zhang et al. (2004), and a decreasing trend of surface solar radiation was found between 1961 and 2000. Che et al. (2005) analyzed the variations in annual mean solar radiation data collected at 64 radiation stations for the period from 1961 to 2000. Liang and Xia (2005) did a similar study only with the data at 42 first-class stations recognized by the CMA. Both studies indicated that there is a decreasing trend of solar radiation in China before the 1990s but it does not persist thereafter. With the same data of the 42 first class stations, Xia et al. (2006) divided China into four regions (South China, North China, Northeast China, and West China) and they found that there are negative trends over all the four regions between 1961 and 2000 while there are positive trends over all the four regions between 1984 and 2000. Furthermore, Averaging over 43 stations in China, Ye et al. (2009) derived the time series of annual mean solar radiation anomalies from 1961 to 2007 and identified a trend transition (from dimming to brightening) at 1990 .

However, the quality control process of the radiation data in the above studies is still primitive or vague. In fact, some recent study results revealed that systematic errors often occur in the radiation measurements. Shi et al. (2008) pointed out that the quality of solar radiation data obtained in China is often doubted. For example, there is an obvious abnormal low solar radiation level presented by the data collected from three Tibetan stations (Naqu, Shiquanhe, and Lhasa) for the period between 1988 and 1992. More abnormal data are found in Tang et al. (2010). The trends reported in previous studies may have been distorted by erroneous observational data. In order to avoid this problem, Shi et al. (2008) introduced a quality control scheme in their study. Upon analyzing the data obtained by 72 radiation stations between 1961 and 2000, they agreed that a trend transition happened in the early 1990s. However, they also pointed out that the transition might be caused by the large scale of retrofit to radiation instruments at CMA stations around the early 1990s. Moreover, using the corresponding climatological values to replace erroneous and suspected data in the measured time series is a step in their quality control scheme, which might also introduce extra uncertainties into their analysis. Norris and Wild (2009) used cloud cover data to exclude suspicious data at 23 radiation stations over China, and reached that surface solar radiation over China decreased by a statistically significant $1.1 \mathrm{~W} \mathrm{~m}^{-2} \mathrm{yr}^{-1}$ between 1971 and 1989 and increased by a non-significant $0.4 \mathrm{~W} \mathrm{~m}^{-2} \mathrm{yr}^{-1}$ between 1990 and 2002. However, they also noticed that their results could not represent the entire country since many areas lacked solar radiation measurements. There are several other factors which may contaminate the trend analysis. The first one is the representative problem with the number of the CMA radiation stations. Though CMA has 122 radiation stations, long-term solar radiation observation stations are sparsely available in the Mainland of China, comparing to the entire China territory and to the number of all CMA routine weather stations. This situation is particularly true in West China. For example, there are only four radiation stations (Lhasa, Shiquanhe, Naqu, and Germu) over the Tibetan Plateau, though its area occupies about one fourth of China. Second, it is always difficult to obtain a quality-consistent long-term dataset for this type of studies, due to the retrofit of obsolete instruments, removal of stations, and poor maintenance of the instruments. Therefore, a strict station selection is of primary importance for better identifying the trend of solar radiation. Third, most of the radiation stations are located in developed urban or suburban areas, and thus, early reported decreasing trends may be not able to represent the ones in vast developing and less polluted areas.

Therefore, it is not straightforward to quantify the radiation trend in China with available radiation data, due to their discontinuity, quality-inconsistency, and nonrepresentativeness. In order to get rid of their potential impacts, this study combines quality-controlled data and two radiation models to estimate the trend of surface solar radiation over China. First, a quality control scheme is adopted to select long-term reliable observation data from 96 radiation stations and the selected dataset is applied to derive true radiation trends at the selected stations. Second, the derived radiation trends are used to verify the capability of the two radiation models when used to estimate the radiation trend. One model is the Artificial Neural Network (ANN) -based model, and the other one is a hybrid model developed in Yang et al. (2006). The ANN-based model is trained with reliable radiation data that are available in recent years and then it is used to extend the radiation records to a long period for each radiation station. This approach extends the trend estimate from a few selected radiation stations to all radiation stations. Moreover, the hybrid model estimates solar radiation from sunshine duration data and other meteorological measurements and it works at all CMA stations, making it possible to estimate the radiation trend across China.

The rest of this paper is organized as follows. Dataset and methods used in this study are described in Sect. 2. Section 3 evaluates the trends produced by the two radiation models against the observed one at the stations with continous and quality-consistent data. In Sect. 4, the spatio-temporal patterns of solar radiation trend over China are given. Section 5 presents comparisons with previous estimates and satellite estimate. Discussions on uncertainties of the methods are presented in Sect. 6 and conclusions are given in Sect. 7. 


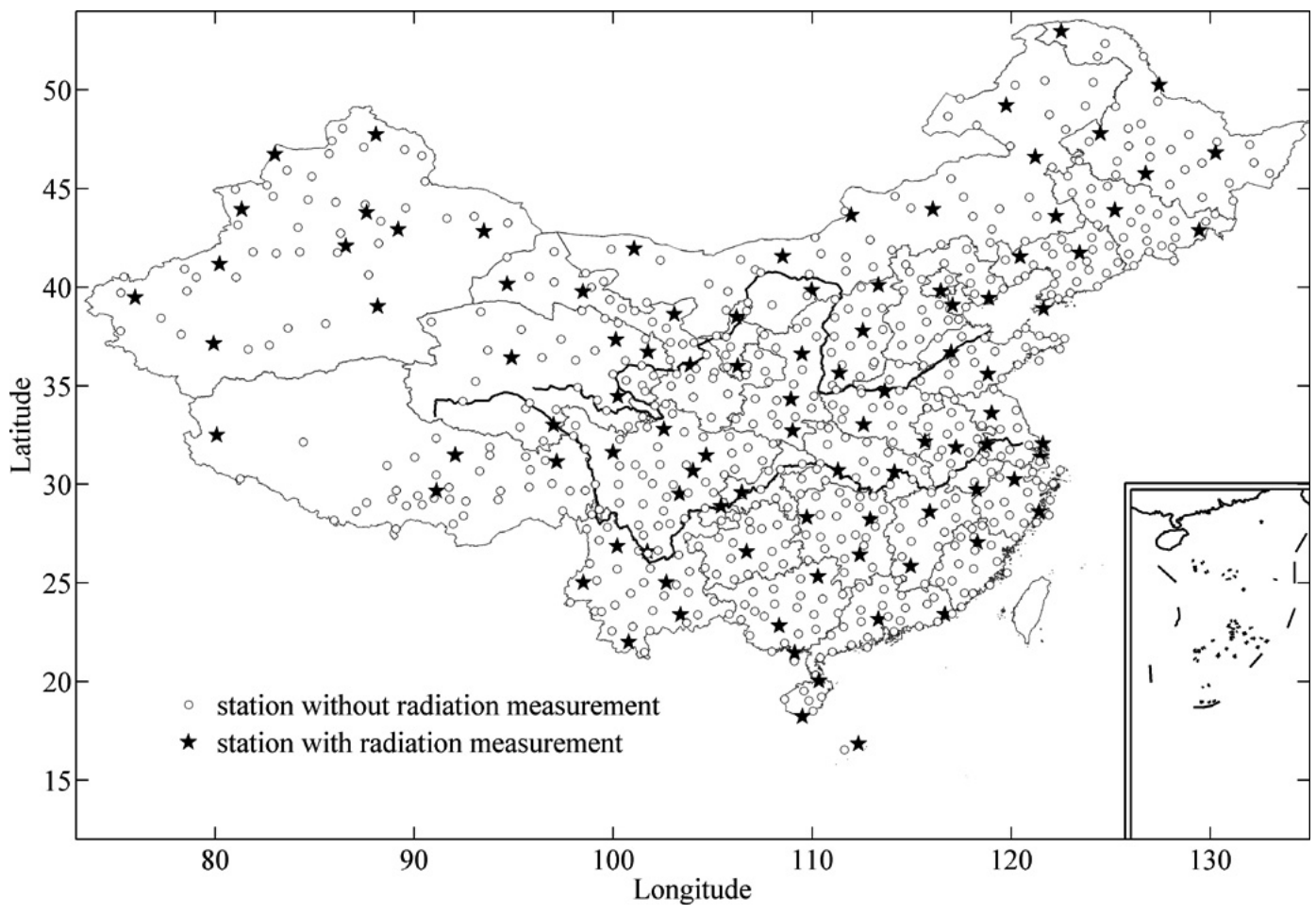

Fig. 1. The spatial distribution of 716 CMA stations, among which there are 96 radiation stations denoted by five-pointed star symbols.

\section{Dataset and methods}

\subsection{Observation data}

Daily meteorological data at 716 CMA routine weather stations were released at the CMA Meteorological Information Center. The data at each station comprise air temperature, air pressure, relative humidity, sunshine duration and precipitation. Solar radiation was first measured in 1957, and then, its measurement was gradually conducted at a total of 122 stations. However, the measurement at some stations stopped in the past. Since 1994, there are 96 stations remaining to measure solar radiation and a new type of radiometer was used at these stations. Figure 1 shows the geographical distribution of 716 stations. Among them, the 96 radiation stations are marked by five-pointed star symbols.

Meanwhile, attention needs to be paid to both availability and quality consistency of the radiation data. Among the 96 stations, "complete records" (defined as a set of data that contain at least 20 days records in every month) between 1961 and 2006 are available only at 16 radiation stations (see Table 1). In the history of CMA radiation measurement, two different types of the radiometers have been used to measure solar radiation before 1994 and afterwards, respectively. One is imitated based on those used in the former Soviet Union, and the other is the so-called DFY-4 manufactured by China. These instruments are calibrated by a set of standard procedures based on a time table (The detailed procedures are described in Yang et al., 2008). The errors of the two pyranometers would not exceed $5 \%$ as pointed out by Shi et al. (2008). However, these standard calibration procedures were not strictly conducted at some stations, especially for the periods from the late 1960s to the early 1980s and from the early 1990s to the middle 1990s (CMA 2005).

This problem is also confirmed in Table 1, which shows the rates of obviously erroneous and suspected data at all 16 radiation stations that have continuous time series for the period of $1961 \sim 2006$. The obviously erroneous and suspected data are identified by two relaxed physical tests. First, the measured radiation should not exceed the extraterrestrial radiation $\left(H_{0}\right)$ and not less than the lower bound $\left(0.03 H_{0}\right.$, according to Geiger et al., 2002). Second, the measured radiation should not exceed the clear-sky daily radiation too much (generally, no more than 10\%). The erroneous and suspected rates for the earlier period $(1961 \sim 1993)$ are clearly greater than those for the latter period (1994 2006), indicating larger measurement uncertainties during the earlier period. Therefore, the radiation trend cannot rely on the measurements without cautious data quality check. Another issue is severe data discontinuity at some radiation stations (not shown), which also limits the application of radiation data in trend analysis.

In the light of these calibration problems before 1994, the radiation data for this period are controlled by a scheme described in Tang et al. (2010). As a result, spurious data and inaccurate measurements in the observations are excluded. 
Table 1. The rates of obviously erroneous and suspected data for two separate time periods (1961 1993 and 1994 2006) at all 16 radiation stations that contain continuous time series from 1961 to 2006. The numbers in parentheses are the rates of data with obvious positive biases. The unit of the rate is percentage $(\%)$.

\begin{tabular}{lllllllll}
\hline Station name & Haerbin & Yining & Urumchi & Tulufan & Hetian & Minqin & Datong & Taiyuan \\
\hline Station code & 50953 & 51431 & 51463 & 51573 & 51828 & 52681 & 53487 & 53772 \\
$1961 \sim 1993$ & $7.33(5.43)$ & $10.13(7.17)$ & $5.16(2.03)$ & $2.22(2.13)$ & $0.91(0.59)$ & $6.05(5.51)$ & $13.38(12.38)$ & $8.37(5.89)$ \\
$1994 \sim 2006$ & $1.22(1.05)$ & $6.09(2.44)$ & $2.99(0.13)$ & $0.48(0.46)$ & $0.23(0)$ & $2.01(1.98)$ & $0.91(0.70)$ & $0.36(0.17)$ \\
Station name & Beijing & Zhengzhou & Yichang & Gushi & Nanjing & Hangzhou & Guangzhou & Shantou \\
Station code & 54511 & 57083 & 57461 & 58208 & 58238 & 58457 & 59287 & 59316 \\
$1961 \sim 1993$ & $10.69(9.26)$ & $4.06(1.09)$ & $7.46(0.25)$ & $9.44(3.43)$ & $6.33(1.79)$ & $8.09(0.32)$ & $4.16(0.23)$ & $1.60(0.03)$ \\
$1994 \sim 2006$ & $2.42(0.76)$ & $2.61(0.02)$ & $5.42(0.04)$ & $1.25(0.25)$ & $2.89(0)$ & $7.37(0.87)$ & $2.70(0)$ & $0.11(0)$ \\
\hline
\end{tabular}

Table 2. The numbers of the stations for different purposes during different time periods in this study. The numbers in parentheses are for the comparison of trend estimates between ANN and the hybrid model.

\begin{tabular}{lccccc}
\hline Radiation data sources & \multicolumn{5}{c}{ Number of stations } \\
\cline { 2 - 6 } & Total & Validation & Analysis & $\begin{array}{c}\text { Comparison with } \\
\text { previous estimates }\end{array}$ & $\begin{array}{c}\text { Comparison with } \\
\text { satellite estimates }\end{array}$ \\
& & $1979 \sim 2006$ & $1961 \sim 2006$ & $1961 \sim 2000$ & $1984 \sim 2006$ \\
Observation & 96 & 10 & - & - & - \\
ANN estimate & 96 & 10 & $-(67)$ & - & - \\
Hybrid estimate & 716 & 10 & $459(67)$ & 459 & 592 \\
\hline
\end{tabular}

After the quality control, there remain only a few stations with "complete records" for a long term, for instance, six stations for the years from 1979 to 2006 . Therefore, we introduce the ANN-based model and the hybrid model to extend the radiation trend analysis to all stations and longer periods, before which the trend estimates are evaluated against the ones derived from these six stations.

\subsection{Data selection for validation, analysis, and inter-comparison}

Three types of stations and periods were selected for different purposes. (1) To validate the estimated trends, the selected radiation stations must contain credible and continuous observation data. Moreover, the number of selected radiation stations cannot be too small and the time series cannot be too short. Therefore, the time period from 1979 to 2006 was selected for the validation. (2) For trend analysis, time series as long as possible is necessary to investigate the possibility of the trend transition from solar dimming to brightening, and thus the time period from 1961 to 2006 was selected. (3) To compare with previous estimates, the period from 1961 to 2000, which was adopted in previous studies, was selected. To compare with the satellite estimate, the period from 1984 to 2006, which is the longest period covered by satellite product, was selected. As different periods are concerned, the numbers of the selected stations are different for the individual purposes, as shown in Table 2.
Considering the possible transition from solar dimming to brightening that was suggested in previous studies, we separated the period into two sub-periods $(1961 \sim 1989$ and $1990 \sim 2006$ ) and investigated the trend in each period. However, this separation is not applied to two cases. First, the validation of the methods (in Sect. 3) hinges on reliable radiation data, which are available only for the period of $1979 \sim 2006$. If this period is divided into two periods, the sample size would be too small and thus leads to large uncertainties. The other case is the trend analysis for the Tibetan Plateau (in Sect. 4), where we find a transition of the radiation trend occurred in 1978 instead of 1989.

\subsection{ANN-based model}

The ANN employed in the present study is a commercial computer package (Demuth et al., 2008). It is an information processing system which is often applied to recognize patterns, fit a function, and cluster data. Recently, many researchers utilized ANN-based models to estimate surface solar radiation (e.g. Tymvios et al., 2006; Mubiru and Banda, 2008; Jiang, 2009). Their results did show its superior performance over the traditional regression methods applying in radiation estimates. In this study, a feed-forward backpropagation (BP) neural network is adopted. It consists of several layers of neurons that are linked with connections. A neuron is a simplified mathematical model like a biological neuron, and a connection is the unique link between the 
sending and the receiving neurons for information transport. The first and last layers of neurons are called input and output layers, respectively. Between these layers are one or more hidden layers. Simply speaking, neurons receive inputs and combine them, and then perform operations and output the final results.

In the present ANN-based modeling, the input layer has six parameters including daily air temperature range, precipitation, sunshine duration, daily mean air temperature, air pressure and relative humidity. The only one hidden layer has 20 neurons equipped with hyperbolic tangent sigmoid transfer function which can be expressed as:

$f(x)=\frac{e^{x}-e^{-x}}{e^{x}+e^{-x}}$

In the last layer, there is only one neuron to produce the output of estimated daily solar radiation and the transfer function of this layer is a logistic sigmoid function which can be expressed in the following:

$f(x)=\frac{1}{1+e^{-x}}$

All of the ANN works are performed by MATLAB neural network toolbox. For more detailed theoretical knowledge of ANN, we can refer to Neural Network Toolbox ${ }^{\mathrm{TM}} 6$ User's Guide (Demuth et al., 2008).

In this study, quality-controlled observation data between 1994 and 2006, which are deemed reliable, are employed to train the ANN-based model at each of the 96 radiation stations. The dataset collected before 1994 are not used for this training, because of its quality issue. The trained model is then applied to trace back the daily solar radiation before 1994 at each radiation station.

\subsection{Hybrid model}

The hybrid model taken in the present study is a physical model which was developed by Yang et al. (2001) and then further improved by Yang et al. (2005, 2006). The latest version of the hybrid model was presented in Yang et al. (2006) and used in this study. The model is described by the following mathematical equations:

$R_{\mathrm{sw}}=R_{\mathrm{sw}, \mathrm{clr}} \tau_{c}$,

$R_{\mathrm{sw}, \mathrm{clr}}=R_{b}+R_{d}$,

$\tau_{c}=0.2505+1.1468 n / N-0.3974(n / N)^{2}$,

where $R_{\mathrm{Sw}}\left(\mathrm{W} \mathrm{m}^{-2}\right)$ is the all-sky daily-mean surface solar radiation, $R_{\mathrm{sw}, \mathrm{clr}}\left(\mathrm{W} \mathrm{m}^{-2}\right)$ is the clear-sky daily-mean surface solar radiation. $\tau_{c}$ is the transmittance to account for scattering and absorption that reduce sunshine duration. $n$ is the actual sunshine duration, and $N$ is the maximum possible sunshine duration. $R_{b}\left(\mathrm{~W} \mathrm{~m}^{-2}\right)$ is the daily-mean direct radiation, and $R_{d}\left(\mathrm{~W} \mathrm{~m}^{-2}\right)$ is the daily-mean diffuse radiation received at ground level under clear skies. They are calculated through the expressions as shown in the followings:

$$
\begin{aligned}
& R_{b}=\frac{1}{t_{2}-t_{1}} \int_{t_{1}}^{t 2} I_{0} \bar{\tau}_{\mathrm{b}} d t, \\
& R_{d}=\frac{1}{t_{2}-t_{1}} \int_{t_{1}}^{t 2} I_{0} \bar{\tau}_{\mathrm{d}} d t,
\end{aligned}
$$

where $I_{0}$ is the solar irradiance on a horizontal level at the top of the atmosphere, $t_{1}$ is the sunrise, and $t_{2}$ is the sunset, $\overline{\tau_{\mathrm{b}}}$ and $\overline{\tau_{\mathrm{d}}}$ are the broadband direct radiative transmittance and the diffuse radiative transmittance. They can be approximated by:

$\bar{\tau}_{\mathrm{b}} \approx \bar{\tau}_{\mathrm{oz}} \bar{\tau}_{\mathrm{w}} \bar{\tau}_{\mathrm{g}} \bar{\tau}_{\mathrm{r}} \bar{\tau}_{\mathrm{b}}$,

$\overline{\tau_{\mathrm{d}}} \approx 0.5 \bar{\tau}_{\mathrm{oz}} \bar{\tau}_{\mathrm{g}} \bar{\tau}_{\mathrm{w}}\left(1-\bar{\tau}_{\mathrm{a}} \bar{\tau}_{\mathrm{r}}\right)$,

where $\bar{\tau}_{\mathrm{r}}, \bar{\tau}_{\mathrm{a}}, \bar{\tau}_{\mathrm{oz}}, \bar{\tau}_{\mathrm{w}}$, and $\bar{\tau}_{\mathrm{g}}$ are, respectively, solar radiation transmittance of five damping processes in the atmospheric layer, viz. Rayleigh scattering, aerosol extinction, ozone absorption, water vapor absorption, and permanent gases absorption. The detailed calculation of these transmittances can be found in Yang et al. (2006).

Inputs of the model are daily mean air temperature, relative humidity, air pressure, sunshine duration, the Ångström turbidity, and the thickness of ozone layer. The Ångström turbidity is produced by the Global Aerosol Data Set 2.2a (GADS) model (Koepke et al., 1997; Hess et al., 1998). The thickness of ozone layer is obtained from Total Ozone Mapping Spectrometer (TOMS) zonal means provided by NASA/GSFC Ozone Processing Team (see http://toms.gsfc. nasa.gov/ozone/ozone_v8.html).

The hybrid model was recognized by many researchers (Gueymard, 2003a, b; Paulescu and Schlett, 2004; Madkour et al., 2006) as one of the best broadband models. It has been also applied to provide solar radiation input data for hydrological modeling in Tang et al. (2007, 2008). In the present study, this hybrid model is applied to expand the radiation dataset to the 716 CMA stations and then estimate the radiation trend in China.

\subsection{Trend analysis method}

In this study, the linear regression is used to determine the trends of solar radiation for both simplicity and comparability with previous trend estimates. In Sect. 5.1, trends obtained with an advanced method (dynamic harmonic regression) will be used to compare with the linear ones and validate the feasibility of the linear regression. The linear regression model can be expressed by

$y=a+b x+e$, 
Table 3. Replacement of the radiation data collecting from four additional radiation stations used for trend validation (see the text).

\begin{tabular}{llllll}
\hline $\begin{array}{l}\text { Station } \\
\text { code }\end{array}$ & Year & $\begin{array}{l}\text { Problem } \\
\text { month }\end{array}$ & $\begin{array}{l}\text { Number of } \\
\text { effective daily } \\
\text { data available in } \\
\text { problem month }\end{array}$ & $\begin{array}{l}\text { Monthly-mean of } \\
\text { observation data } \\
\left(\mathrm{W} \mathrm{m}^{-2}\right)\end{array}$ & $\begin{array}{l}\text { Monthly-mean of } \\
\text { ANN estimates } \\
\left(\mathrm{W} \mathrm{m}^{-2}\right)\end{array}$ \\
\hline 53614 & 1987 & 9 & 12 & 191.4 & 205.3 \\
56959 & 1995 & 8 & 11 & 175.2 & 158.4 \\
58208 & 1990 & 7 & 18 & 249.8 & 223.2 \\
59287 & 1983 & 2 & 16 & 64.9 & 53.1 \\
& 1983 & 3 & 19 & 84.6 & 71.7 \\
& 1990 & 12 & 14 & 106.5 & 127.4 \\
\hline
\end{tabular}

where $y$ denotes the time series of surface solar radiation, $x$ the time series of years, $e$ the residuals, $a$ the intercept, and $b$ the slope (decreasing or increasing rate). The regression parameters $a$ and $b$ are determined by the least-square fitting. The confidence levels of the trend slope are determined according to the Student's $t$-test with the following mathematical expression:

$t=r\left[(n-2) /\left(1-r^{2}\right)\right]^{1 / 2}$,

where $r$ is the correlation coefficient between the observed time series and the fitted time series, and $n$ is the total number of years.

The $95 \%$ confidence intervals of the trend slope can be given by the range from from $b-1.96(\mathrm{SE})$ to $b+1.96(\mathrm{SE})$ according to Wigley (2006). SE denotes the standard deviation of the distribution of $b$, and the formula for SE is:

$\mathrm{SE}=\left\{\frac{1}{(n-2)} \cdot\left[\sum\left(e^{2}\right)\right] /\left[\sum\left((x-\bar{x})^{2}\right)\right]\right\}^{1 / 2}$,

where $\bar{x}$ denotes the mean value of $x$.

\section{Validation of radiation trends in the models}

In order to use the estimated solar radiation to re-evaluate the long-term trends, we need to validate the trends of the estimated against the observed ones. After the quality control, only six stations' data taken from 1979 to 2006 have "complete records" and consistent quality. In order to enhance the representation of the validation dataset, other four stations, which have "complete records" except for a few months (no more than three months from 1979 to 2006), are also selected. The monthly-mean values of these months are replaced by the ANN estimated ones. Details of these replacements are listed in Table 3. The ten selected radiation stations are: Beijing, Geermu, Guangzhou, Gushi, Jinghong, Nanjing, Tulufan, Urumchi, Yinchuan, and Zhengzhou. Radiation data collected at these stations provide the validation basis.
Figure 2 shows the comparison of the annual mean solar irradiance time series during 1979 2006 among the observed, the estimated by the ANN-based model, and the estimated by the hybrid model at the ten validation stations selected above. It can be found that the estimated values by the ANN-based model are close to the observed ones. The hybrid model also produces similar inter-annual variability though it slightly overestimated the values. The trends derived from the two models are compared with the observed ones in Fig. 3. It is shown that the model-derived trends are comparable to the observed ones, and their correlation coefficients are greater than $0.85(p<0.01)$. These high correlation values demonstrate that the two models can be used to estimate surface solar radiation trend.

In order to obtain the radiation trends at more stations, the two models are then applied to all radiation stations. During the period from 1961 to 2006 , only 67 radiation stations have "complete records" of meteorological parameters that are required to apply the two models. Figure 4 compares the trends derived by the two models at the 67 radiation stations during $1961 \sim 2006$. We can find that the trends derived by the two independent models match each other very well and their correlation coefficient is up to $0.93(p<0.01)$. Therefore, the hybrid model is believed to be capable of reproducing the trend of surface solar radiation.

\section{Trend of surface solar radiation over China}

Based on the above reasoning, the hybrid model is used to extend the trend analysis to all CMA stations. Although there are 716 CMA stations, only 459 stations can provide "complete records" for the years from 1961 to 2006. In this section, discussed are the results at the 459 stations.

Figure $5 \mathrm{a} \sim \mathrm{b}$ shows the spatial distributions of the trend slopes in surface solar radiation at the 459 stations with "complete records" for the years from 1961 to 1989 , and for the years from 1990 to 2006 . For the time period between 1961 and 1989, negative trend slopes are seen at 380 stations and are statistically significant at 195 of them. The trend 

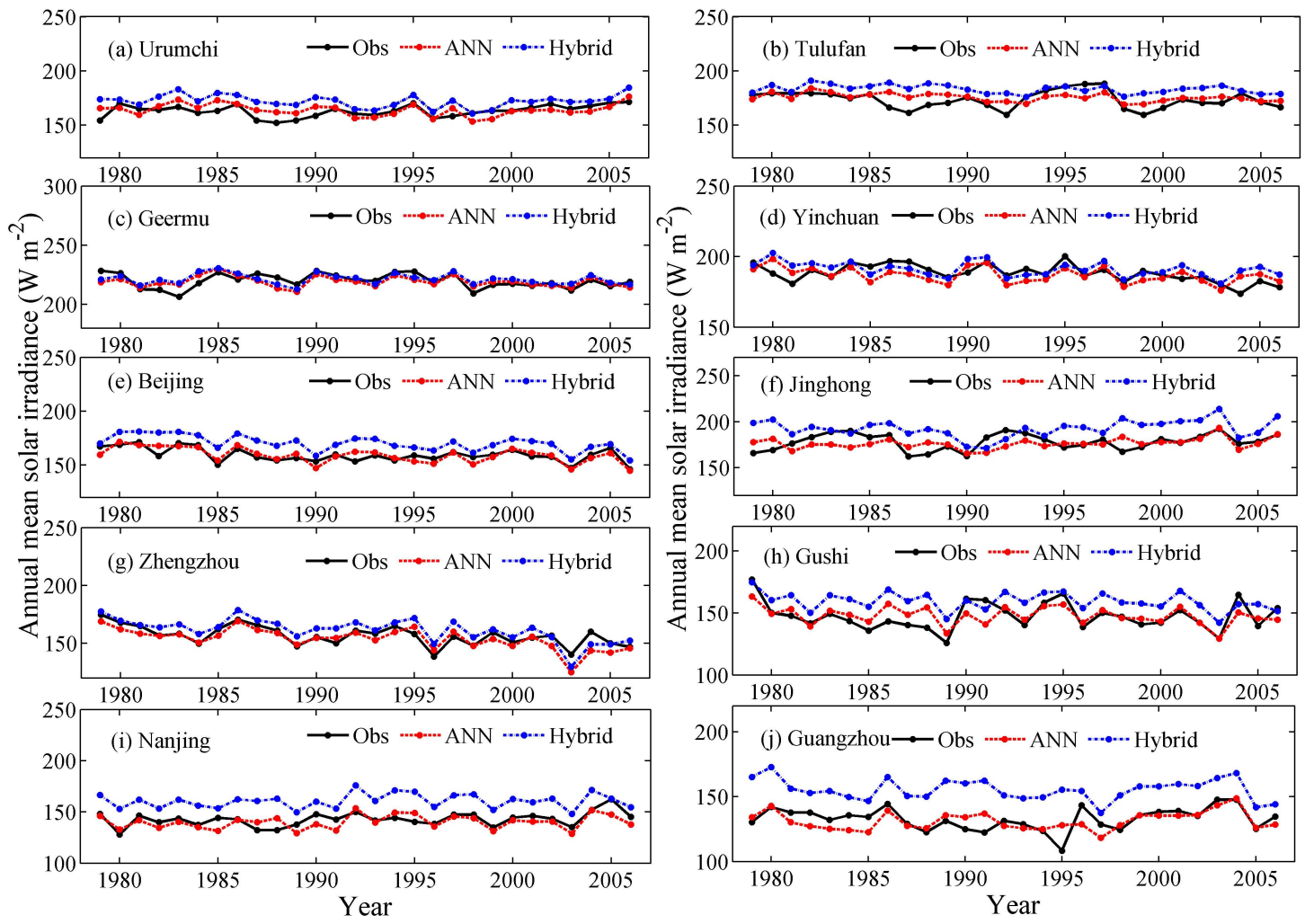

Fig. 2. Comparison of the annual mean solar irradiance time series between 1979 and 2006 among the observed, the estimated by the ANN-based model, and the estimated by the hybrid model at ten radiation stations with "complete records".
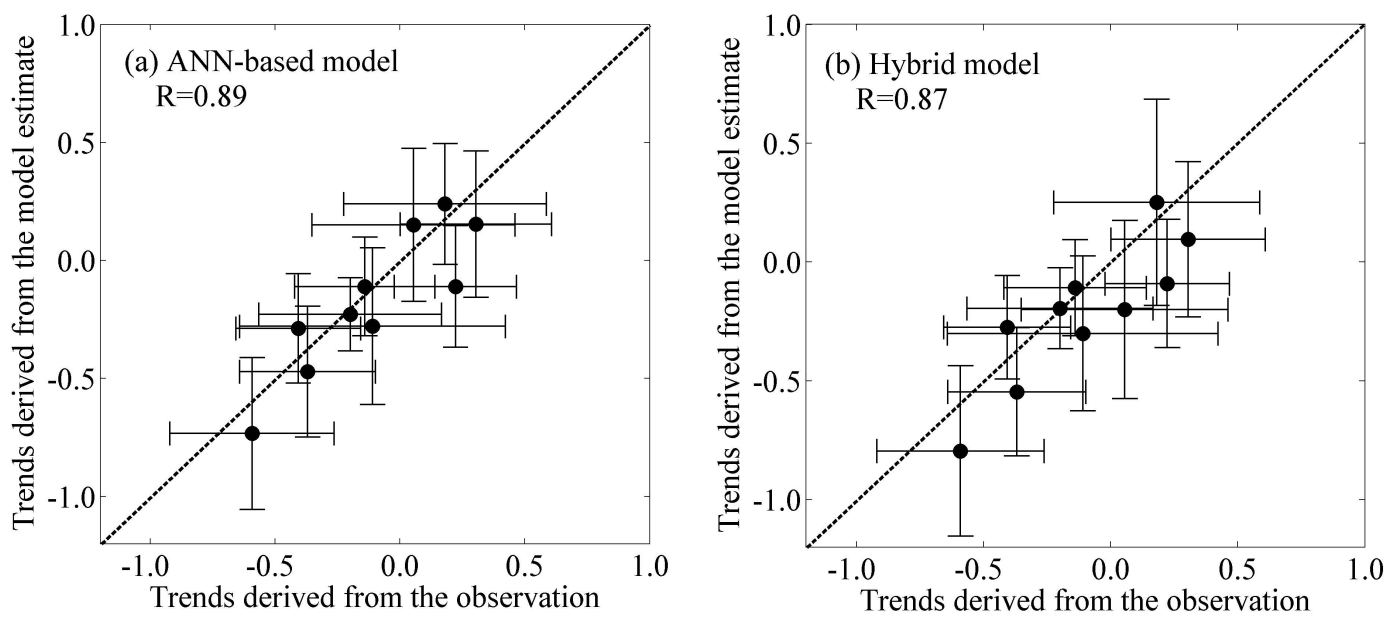

Fig. 3. Comparison of solar radiation trend slopes at ten validation stations during 1979 2006: (a) between the observation and the ANNbased model estimate, and (b) between the observation and the hybrid model estimate. The filled black circles denote trend slopes, and the bars denote the $95 \%$ confidence intervals of the estimated trend slopes. The unit of the trend is $\mathrm{W} \mathrm{m}^{-2} \mathrm{yr}^{-1}$.

slopes at the other 79 stations are positive and are statistically significant at 20 of them. For the time period between 1990 and 2006, negative trend slopes are seen at 211 stations and are statistically significant at 74 of them. The trend slopes at the other 248 stations are positive and are statistically sig- nificant at 68 of them. During the period between 1961 and 1989, "dimming" occurred over most of China, especially in southern China, and "brightening" mainly occurred over parts of the Tibetan Plateau. During the period between 1990 and 2006, "dimming" mainly occurred over most of North 


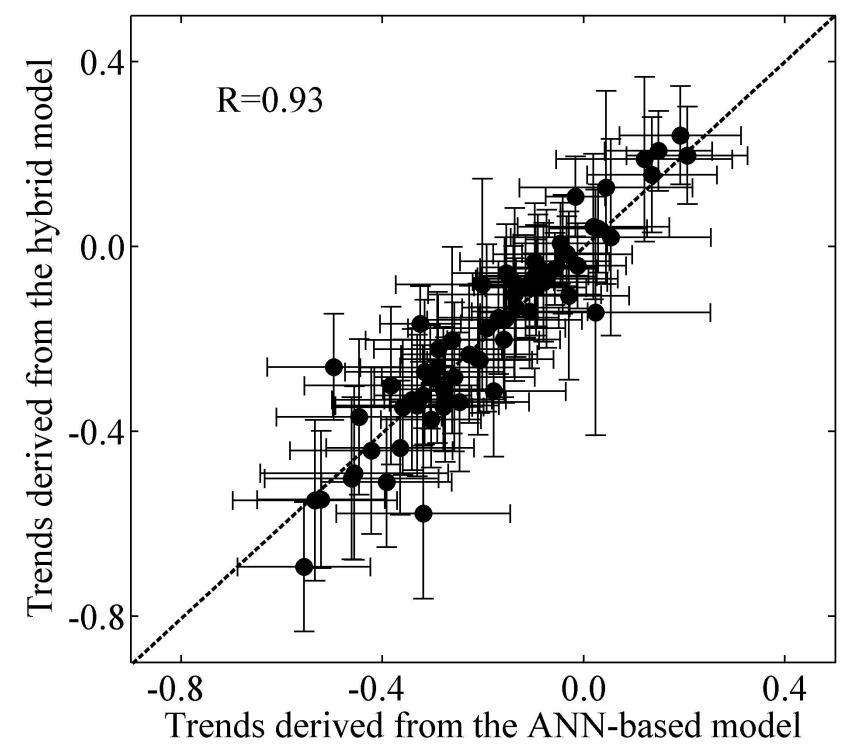

Fig. 4. Comparison of trend slopes in solar radiation estimates between the ANN-based model and the hybrid model at all radiation stations during $1961 \sim 2006$. The filled black circles denote trend slopes, and the bars denote the $95 \%$ confidence intervals of the estimated trend slopes. The unit of the trend is $\mathrm{W} \mathrm{m}^{-2} \mathrm{yr}^{-1}$.

China Plain and the Tibetan Plateau, and "brightening" occurred in Yunnan Province, Guangxi Province, part of Xinjiang Uygur Autonomous Region, Inner Mongolia, Guangdong Province, Gansu Province, and Shaanxi Province.

Figure 6 shows the variations of the solar radiation averaged over all CMA stations in the entire China between 1961 and 2006, with the fitted linear curve. The linear trend between 1961 and 1989 is negative and it is about $-0.25 \pm 0.11 \mathrm{~W} \mathrm{~m}^{-2} \mathrm{yr}^{-1}$ with significance at a $95 \%$ level of confidence. However, the linear trend between 1990 and 2006 is $0.04 \pm 0.16$ (which is negligible), suggesting that the transition from dimming to brightening during the late 1980s to the early 1990s did not apparently happen in our result, though it was reported in previous studies (Che et al., 2005; Liang et al., 2005; Shi et al., 2008; Ye et al., 2009). In fact, the decreasing trend just slowed down and reached a steadily low level after the 1990s. This difference can be attributed to the inconsistent quality of the data used in the previous studies. As shown in Tang et al. (2010), there was an abruptly increase at some stations around $1993 \sim 1994$, when CMA upgraded its radiometers. The "jump" of the measured radiation, however, is not found in the radiation values derived from the ANN-based model and the hybrid model.

As indicated by Wang et al. (2009), aerosol loads increased on average over all continental regions between 1979 and 2006, which was especially obvious in South and East Asia (including India and China). This seems to be a possible reason for the decline of surface solar radiation across China in recent decades. However, this does not help explain
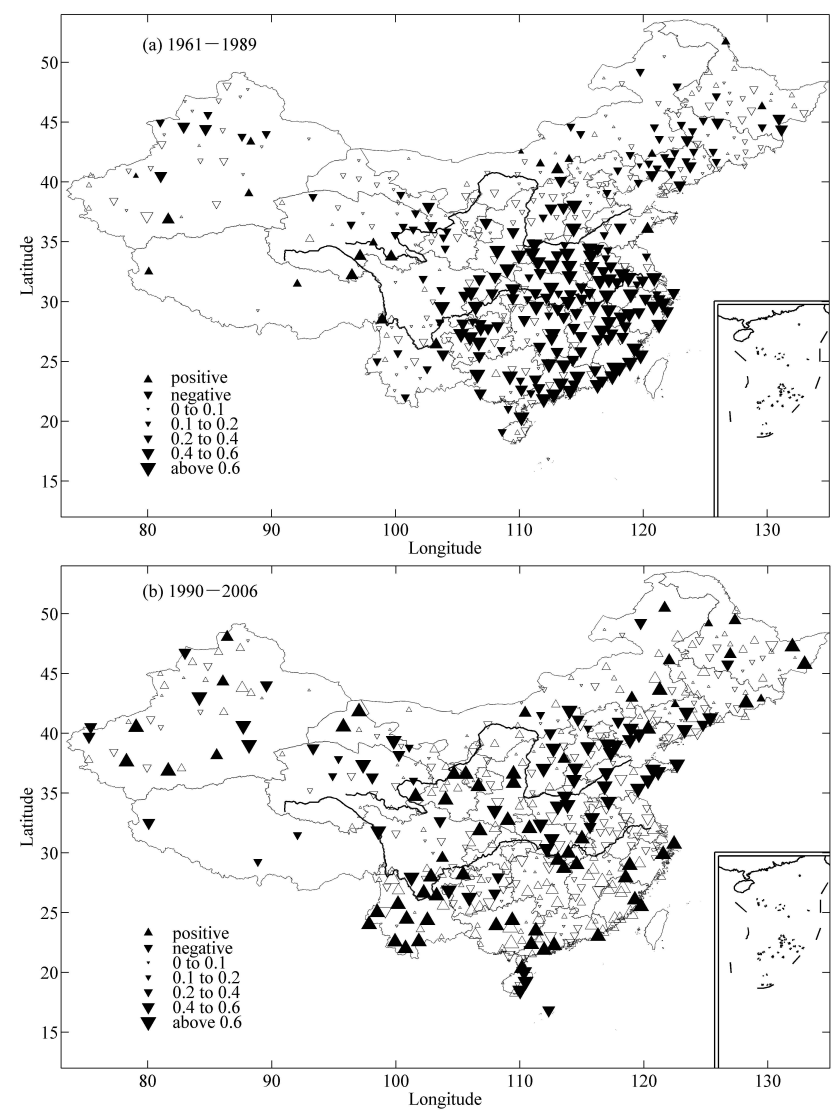

Fig. 5. Spatial distribution of the trend slopes of annual mean solar irradiance estimated by the hybrid model at CMA stations: (a) from 1961 to 1989 , and (b) from 1990 to 2006 . The derived trends for $1990 \sim 2006$ may have larger uncertainties due to the small size of samples. The solid triangle symbol means a trend that passes the significance test $(p<0.05)$.

the decrease of solar radiation in the Tibetan Plateau, where human activities are still limited as far as the aerosol loads are concerned. The Tibetan Plateau has very low aerosol loads (Cong et al., 2009), which provides a unique condition to identify the effect of cloud change on the solar radiation trend. According to our statistics, "complete records" for the years between 1961 and 2006 are available at 38 stations over the Tibetan Plateau. Figure 6 presents the variation of annual mean surface solar radiation averaged over the Tibetan Plateau during $1961 \sim 2006$. There exists an obvious trend transition from brightening to dimming around 1978 over the Plateau. An increasing trend about $0.17 \pm 0.19 \mathrm{~W} \mathrm{~m}^{-2}$ $\mathrm{yr}^{-1}$ is found over the Plateau during $1961 \sim 1978$, suggesting solar radiation change over the Plateau is different from that over the entire China during this period. Since 1979, decreasing trends occurred at both the Plateau scale (about $-0.22 \pm 0.12 \mathrm{~W} \mathrm{~m}^{-2} \mathrm{yr}^{-1}$ ) and at the regional scale of China (about $-0.11 \pm 0.09 \mathrm{~W} \mathrm{~m}^{-2} \mathrm{yr}^{-1}$ ), and the magnitude of the trend for the Plateau is even larger than that for the whole 


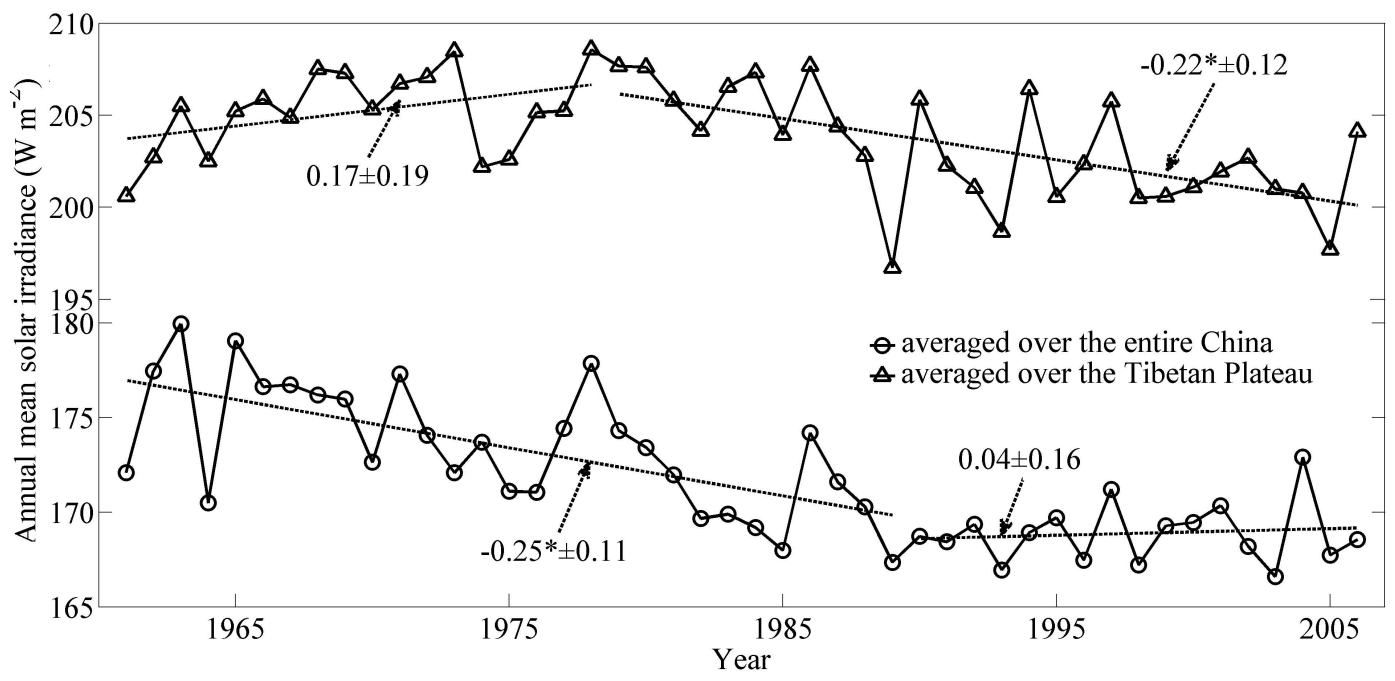

Fig. 6. The hybrid model-derived time series of the annual mean solar irradiance averaged over the entire China and averaged over the Tibetan Plateau during $1961 \sim 2006$. The star symbol $\left(^{*}\right)$ denotes a trend that passes the significance test $(p<0.05)$. The unit of the trend is $\mathrm{W} \mathrm{m}^{-2} \mathrm{yr}^{-1}$.

China. Therefore, the decrease in surface solar radiation over China could not be merely simply explained by the increasing aerosol emissions and may happen under a large-scale background for the whole climatic change.

\section{Comparisons with previous studies and satellite estimate}

\subsection{Comparisons with previous estimates}

Several previously reported trend slopes of surface solar radiation across China between 1961 and 2000 are compared with our result in Table 4 . The number of radiation stations used in each study is also indicated in this table. The values reported by other studies are ranged from -0.41 to $-0.52 \mathrm{~W} \mathrm{~m}^{-2} \mathrm{yr}^{-1}$, which are significantly greater in magnitude than the one in this study $\left(-0.23 \mathrm{~W} \mathrm{~m}^{-2} \mathrm{yr}^{-1}\right)$. This large discrepancy is mainly attributed to some shortcomings and uncertainties in the previous studies, as explained below.

First, the large scale of new instruments retrofit to the CMA radiation stations around the early 1990s and irregular calibration operations might have introduced inconsistency in data quality, but the observed radiation data without data quality control were used for the trend analysis in some previous studies. Some studies may have introduced a quality control scheme in their investigation, but uncertainties still presented, as substitution of erroneous data by climatological values were applied to produce their final results. To give a more quantitative evaluation, we used the original data at the 16 stations in Table 1 to estimate the trend for the period of $1961 \sim 2000$, and produced a trend of $-0.50 \pm 0.14 \mathrm{~W} \mathrm{~m}^{-2} \mathrm{yr}^{-1}$, which is close to previous es-
Table 4. Comparison of solar radiation trend slopes across China during $1961 \sim 2000$ between previous reports and present study.

\begin{tabular}{lrl}
\hline Authors & $\begin{array}{r}\text { Collected observation data } \\
\text { (Number of Stations) }\end{array}$ & $\begin{array}{l}\text { Trend slopes } \\
\left(\mathrm{W} \mathrm{m}^{-2} \mathrm{yr}^{-1}\right)\end{array}$ \\
\hline Che et al. (2005) & 64 & -0.45 \\
Liang et al. (2005) & 42 & -0.52 \\
Shi et al. (2008) & 72 & -0.41 \\
Present $^{1}$ & 459 & -0.23 \\
Present $^{2}$ & 71 & -0.21 \\
Present $^{3}$ & 72 & -0.21 \\
\hline
\end{tabular}

1 denotes the trend slope derived by the hybrid model at 459 CMA stations.

2 denotes the trend slope derived by the ANN-based model at 71 radiation stations.

${ }^{3}$ denotes the trend slope derived by the hybrid model at 72 radiation stations.

timates. However, there are more erroneous and suspected data in the earlier period, as shown in Table 1. In particular, the rates of data with obvious positive biases during the earlier period $(1961 \sim 1993)$ are generally greater than those during the latter period (1994 2006). Including these biased data would lead to a trend larger in magnitude than the truth.

Second, data provided by a station is not always at the same location in some cases because this station moved from one place to another one. For example: Yantai was moved to Fushan in 1992; Chongqing moved to Shapingba in 1988; Changsha relocated in the same city in 1988; and Longhua (Shanghai) relocated within Shanghai in 1991. Unfortunately, these stations were used for trend analysis in some previous studies. All these uncertainties or problems may have distorted the radiation trend, but they are largely avoided in the present study. 


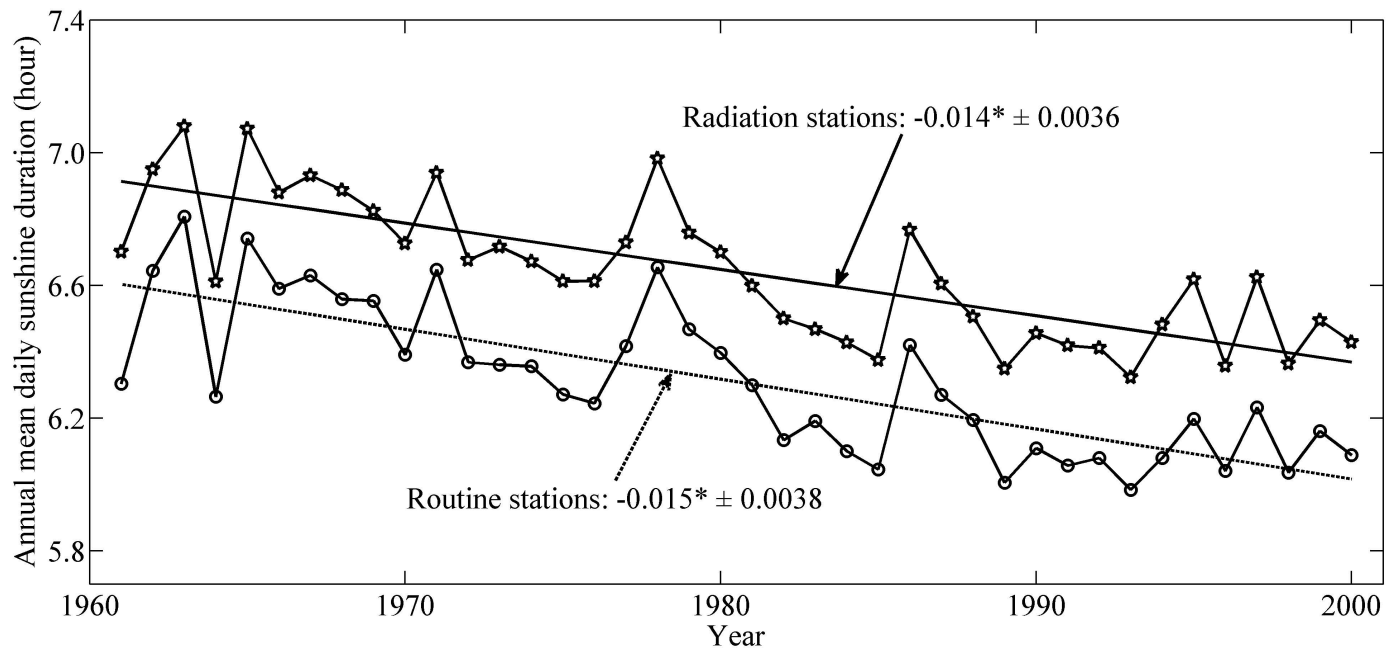

Fig. 7. Time series of annual mean daily sunshine duration during $1961 \sim 2000$. The five-pointed star symbols denote values averaged over all radiation stations, and the circle symbols denote values averaged over all CMA routine stations. The star symbol $(*)$ denotes a trend that passes the significance test $(p<0.05)$. The unit of the trend is hour year ${ }^{-1}$.

One may suppose that the trend difference between this study and previous studies may be partially attributed to the representativeness of the stations used. Previous studies only used the sparsely distributed radiation stations while this study used all available routine meteorological stations. Theoretically speaking, the latter will be more representative of the whole China. To quantify the effect of the representativeness of the radiation stations on the trend over China, we re-calculate the trend slope at the 71 radiation stations between 1961 and 2000 by the ANN-based model and the one at 72 radiation stations by the hybrid model. The averaged trend slopes derived by the two models are both $-0.21 \mathrm{~W} \mathrm{~m}^{-2} \mathrm{yr}^{-1}$. In other words, only a small part of the trend slope difference between this study and previous studies can be accounted for by the limited representativeness of the radiation stations. To further show this issue, Fig. $7 \mathrm{com}-$ pares the sunshine duration trends between the average over all the radiation stations and the one over all the CMA routine stations during $1961 \sim 2000$, indicating both are similar to each other. Again, this indicates that the trend slope represented at the radiation stations can represent the one in the entire China approximately.

In summary, the significantly more negative trend slopes in previous studies are not mainly attributed to the representativeness of the radiation stations but the inconsistent quality of the original radiation data.

\subsection{Comparisons with satellite-based estimate}

The globally-available Global Energy and Water Cycle Experiments-Surface Radiation Budget (GEWEX-SRB; Cox et al., 2006) product provides the possibility to estimate the radiation trend worldwide. Figure 8 compares the annual mean solar irradiance time series from 1984 to 2006 averaged over the 592 stations between the satellites estimates and the hybrid model estimates. Both estimates exhibit that surface solar radiation over China experiences a decreasing process, but the satellite-derived trend slope is much larger in magnitude than the one derived by the hybrid model. This could indicate that the trend derived from the GEWEX-SRB product over the entire China is overestimated. To further verify this, Fig. 9 shows the trend slopes comparison between the satellite estimate and the observation at the ten validation stations selected in Sect. 3. The trend slopes derived from the GEWEX-SRB product are negative at all the ten validation stations, and most of them are inconsistent with the observed ones. Their correlation coefficient is only 0.12 . Therefore, the ability of satellites to explore variations of surface solar radiation needs to be improved, at least over China. This result is consistent with the point made by Norris and Wild (2007) that satellite-based surface radiation records are not reliable for trends, both due to the lack of time-varying aerosol and due to artifacts in the satellite cloud record.

\section{Discussions on method uncertainties}

\subsection{Analyzing trend with dynamic harmonic regression}

To investigate whether a linear fitting can capture the variations of surface solar radiation effectively, a more advanced method, dynamic harmonic regression (DHR), was used to 


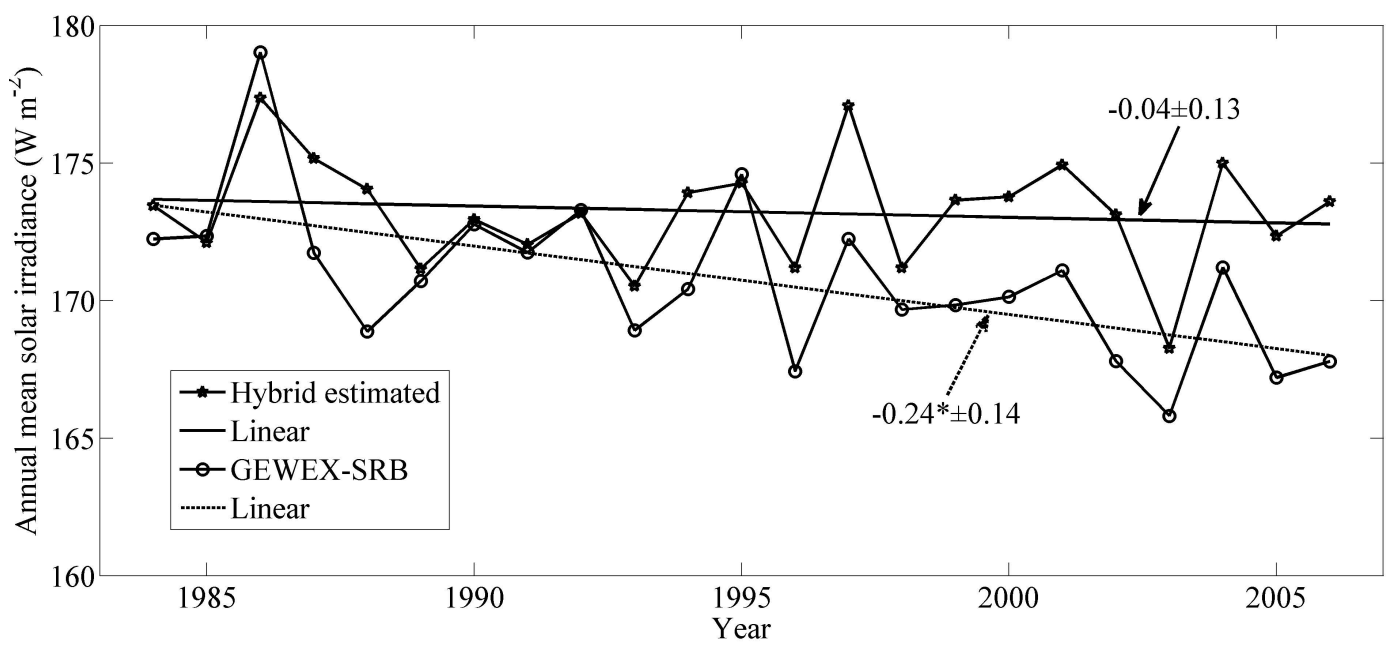

Fig. 8. Comparison of annual mean solar irradiance during 1984 2006 between the satellite estimates (GEWEX-SRB) and the hybrid model estimates averaged over CMA routine stations. The star symbol $(*)$ denotes a trend that passes the significance test $(p<0.05)$. The unit of the trend is $\mathrm{W} \mathrm{m}^{-2} \mathrm{yr}^{-1}$.

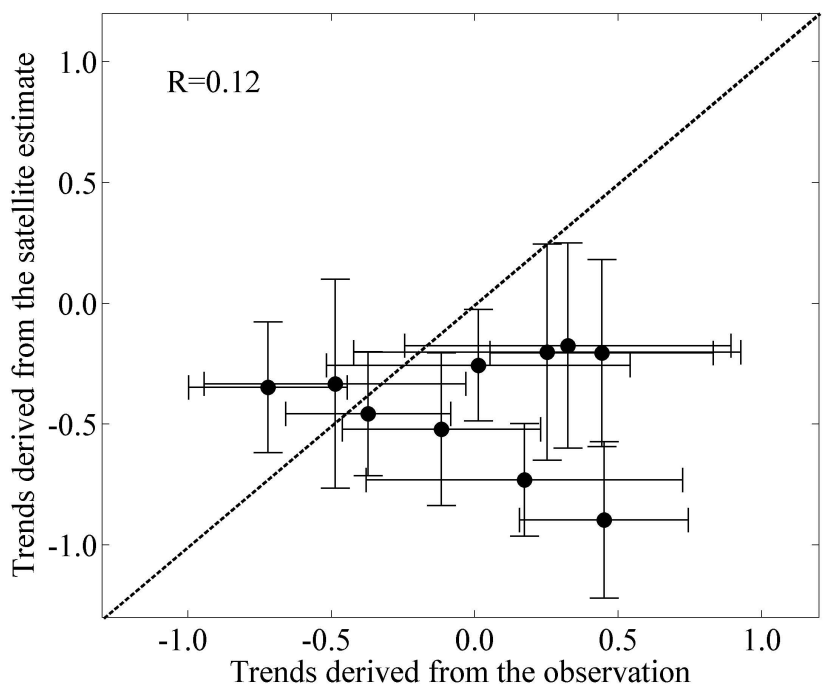

Fig. 9. Comparison of radiation trend slopes during 1984 2006 between the observation and the GEWEX-SRB product at ten validation stations. The filled black circles denote trend slopes, and the bars denote the $95 \%$ confidence intervals of the estimated trend slopes. The unit of the trend is $\mathrm{W} \mathrm{m}^{-2} \mathrm{yr}^{-1}$.

compare with the linear fitting in this sub-section. DHR is a sophisticated statistical time-series tool and can be used to provide long-term trend information and forecast scenarios. The detail of the model can be found in previous studies (Young et al., 1999; Tych et al., 2002; Becker et al., 2008). The DHR model contains the trend, cyclical, seasonal and white noise components, and can be expressed by the basic equation

$y_{t}=T_{t}+S_{t}+C_{t}+e_{t}$, where $y_{t}$ is the observed time series (here: surface solar radiation). $T_{t}$ is a low-frequency component, describing the long-term variation, $S_{t}$ is the seasonal component, $C_{t}$ is the cyclical component (normally longer period), and $e_{t}$ is an irregular or "noise" component describing model residuals. In this study, $S_{t}$ does not exist because our data are annual mean values.

In order to isolate the trend, the first step in the analysis is to identify the most significant harmonics in the series by means of auto-regressive spectrum analyzing. These cyclical terms are then removed using a combination of a Kalman filter and a fixed interval smoother. Finally, the trend is derived with the adjusted data (i.e. the raw data with the cyclical component removed). Actually, the Integrated Random Walk (IRW), which is the subset of DHR model, was used to calculated trend in this study since seasonality $\left(S_{t}\right)$ does not exist.

For brevity, we only choose the annual mean time series of surface solar radiation averaged over all CMA stations during $1961 \sim 2006$. Figure 10 compares the trend derived by the DHR with that by the linear fitting. Clearly, the two trends are very close to each other between 1961 and 1989. Also, the trends from the two methods since 1990 are essentially consistent: the DHR produces a weaker trend with large uncertainties and the linear fitting gives a trend that does not pass the significance test $(p<0.05)$. Therefore, the linear regression method can approximately provide the trend information in solar radiation.

\subsection{Effect of model uncertainties on trend estimate}

Model uncertainties may affect the trend estimate. The ANN-based model has higher accuracy than the hybrid model, and thus we use the latter to analyze this effect. The 


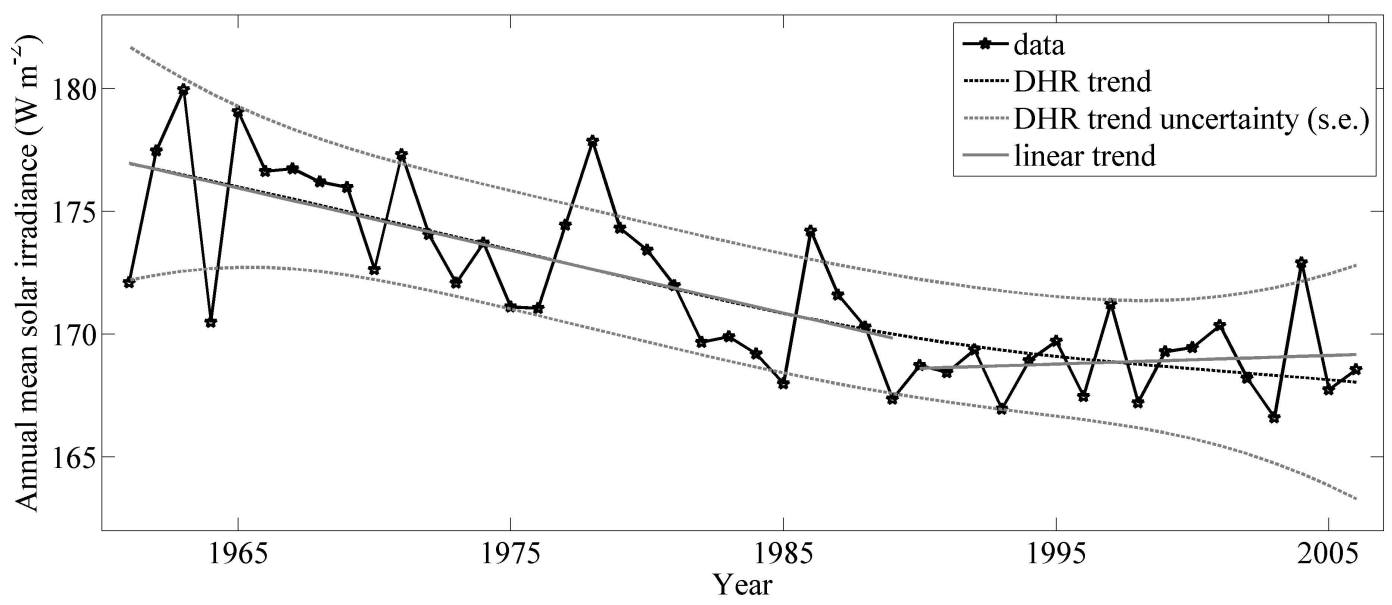

Fig. 10. Comparison of the solar radiation trends derived from the linear regression with that derived from the DHR method. The time series are derived from the annual mean solar irradiance averaged over all CMA stations during 1961 2006. "s.e." denotes standard deviation of the trend estimate, and uncertainty is given at $90 \%$ confidence limits.

hybrid model is constructed based upon a spectral radiative transfer model for clear skies, and its major uncertainty comes from tuning two parameters in the model to link sunshine duration with solar radiation. The calibrated parameters are $a$ and $b$ in the following expression (other parts are essential physical and so not discussed):

$\tau_{c}=a+b(n / N)+(1-a-b)(n / N)^{2}$

To specify the uncertainty of the parameters, we select seven stations of the National Oceanic and Atmospheric Administration's (NOAA's) Surface Radiation Budget Network (SURFRAD), which have high-quality radiation data between 1997 and 2008 (downloaded from http://www. srrb.noaa.gov/surfrad/index.html), to analyze the uncertainty bounds of the parameters. The result is $a=0.2505 \pm 0.0181$ and $b=1.1468 \pm 0.0529$ at a $95 \%$ confidence level. In this study, we have used $\tau_{c}=0.2505+1.1468(n / N)-$ $0.3974(n / N)^{2}$ to calculate the surface solar radiation. To investigate the influence of the model uncertainty, we chose four extreme conditions (taking the upper and lower bounds of parameters $a$ and $b$ ) to re-calculate the surface solar radiation at 716 stations. The mathematical expressions of the default (Case0) and the four extreme conditions (Case1 $\sim$ Case 4 ) are given below:

$$
\begin{aligned}
& \text { Case } 0: \tau_{c}=0.2505+1.1468(n / N)-0.3974(n / N)^{2}, \\
& \text { Case1 }: \tau_{c}=0.2324+1.0939(n / N)-0.3263(n / N)^{2}, \\
& \text { Case } 2: \tau_{c}=0.2324+1.1997(n / N)-0.4321(n / N)^{2}, \\
& \text { Case3 }: \tau_{c}=0.2686+1.0939(n / N)-0.3625(n / N)^{2}, \\
& \text { Case4 }: \tau_{c}=0.2686+1.1997(n / N)-0.4683(n / N)^{2}
\end{aligned}
$$

Figure 11 shows the differences between the default case and the four extreme cases for time series during $1961 \sim 2006$ averaged over all CMA stations. The trends in the differences are negligible, and therefore, the estimated trends for the four extreme cases do not show any distinctive difference with the one for the default case. Other combinations of the two parameters should produce trends similar to the default one. Therefore, the uncertainties of the model parameters negligibly affect the trend estimate, though the magnitude of solar radiation has an uncertainty of several $\mathrm{W} \mathrm{m}^{-2}$.

\section{Conclusions}

In this study, we revisited the solar radiation trend over China by radiation observations and two radiation models. One is the ANN-based model, which can estimate surface solar radiation at all radiation stations, and the other is a physical model, which can estimate surface solar radiation at all 716 CMA stations from sunshine duration data and other routine meteorological data. These two models prove to be able to estimate the radiation trend after the evaluation against observed radiation trends at ten stations with reliable long-term radiation records. The two models also show comparable estimates of the radiation trends at other radiation stations, and thus the hybrid model provides a means to estimate the radiation trend from routine meteorological data at all CMA stations.

The new estimate confirms that there was a decline of surface solar radiation in the entire China since the 1960s, as indicated in previous studies. However, this study suggests the trend slope is $-0.23 \mathrm{~W} \mathrm{~m}^{-2} \mathrm{yr}^{-1}$ between 1961 and 2000 , whereas previous studies gave much larger values in magnitude, ranging from -0.41 to $-0.52 \mathrm{~W} \mathrm{~m}^{-2} \mathrm{yr}^{-1}$. Meanwhile, it is found that the trend over China was also overestimated by the GEWEX-SRB satellite product. Another striking result that differs from previous studies is that the radiation reached a stable level since 1990, and the phenomenon of the transition from dimming to brightening around the year 


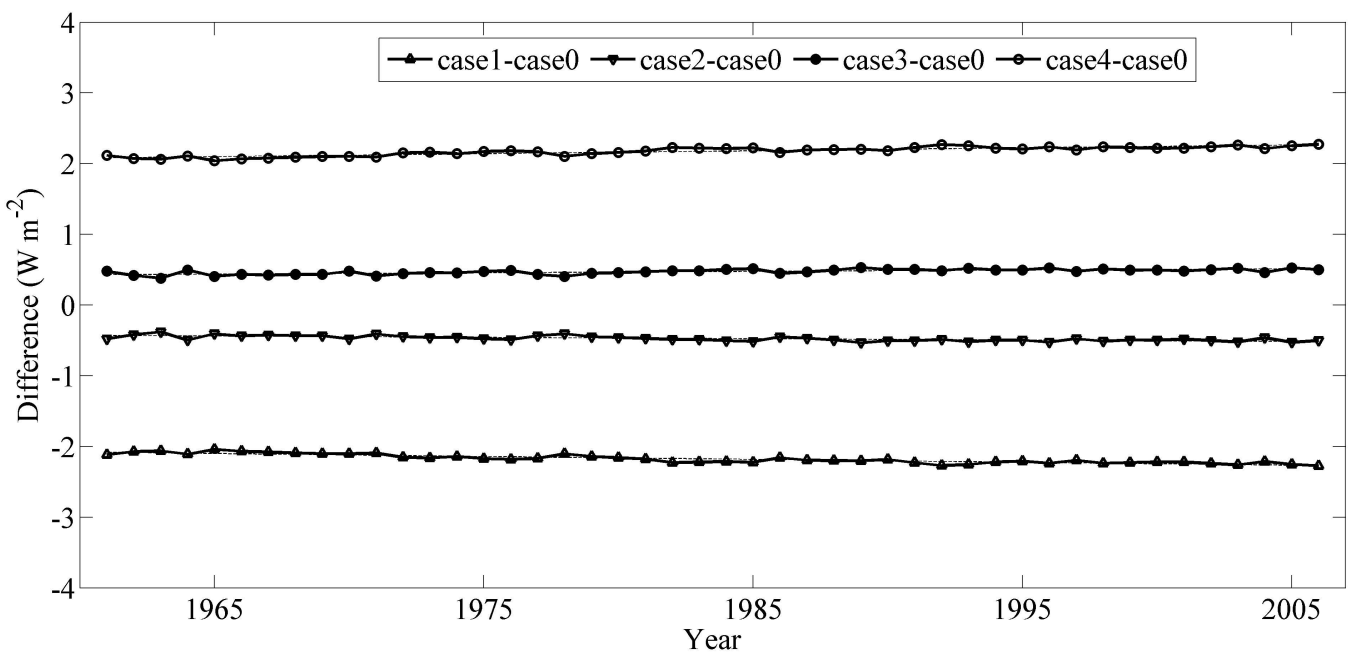

Fig. 11. The differences between the default case and the four extreme cases for the time series between 1961 and 2006 averaged over all CMA stations. The five cases are explained in the text.

1990 in China was not observed, at least not significant, although it was reported in several previous studies. Previous conclusions possibly resulted from radiation data with poor quality, since erroneous and suspected data often exist. In contrast, the new trend slope excluded this deficiency with the aid of the models.

Increasing emissions of aerosols might contribute to the decline of surface solar radiation over the entire China in recent decades. However, the aerosol loads made by human activities are still negligible in the Tibetan Plateau, but the decrease of solar radiation over the Plateau was larger in magnitude than that of the whole China since the end of the 1970s. This phenomenon cannot be fully explained by the increasing emission of aerosols, and further investigations are needed to understand the radiation variations over China.

Acknowledgements. This research was financially supported by grants from National Basic Research Program of China (Grant No. 2009CB723901), Global Change Program of Ministry of Science and Technology of China (2010CB951703), and the "100-Talent" Program of Chinese Academy of Sciences. The routine meteorological data used in this study were obtained from the CMA Meteorological Information Center. We appreciate valuable comments and suggestions provided by the reviewers, which helped improve the quality of this paper.

\section{Edited by: R. MacKenzie}

\section{References}

Abakumova, G. M., Feigelson, E. M., Russak, V., and Stadnik, V. V.: Evaluation of long-term changes in radiation, cloudiness, and surface temperature on the territory of the former Soviet Union, J. Climate, 9, 1319-1327, 1996.

Becker, S., Halsall, C. J., Tych, W., Kallenborn, R., Su, Y., and Hung, H.: Long-term trends in atmospheric concentrations of a- and $\mathrm{g}-\mathrm{HCH}$ in the Arctic provide insight into the effects of legislation and climatic fluctuations on contaminant levels, Atmos. Environ., 42, 8225-8233, 2008.

Che, H. Z., Shi, G. Y., Zhang, X. Y., Arimoto, R., Zhao, J. Q., Xu, L., Wang, B., and Chen, Z. H.: Analysis of 40 years of solar radiation data from China, 1961-2000, Geophys. Res. Lett., 32, L06803, doi:10.1029/2004GL022322, 2005.

China Meteorological Administration: radiation data explain, 2005 (in Chinese) .

Cong, Z., Kang, S., Smirnov, A., and Holben, B.: Aerosol optical properties at Nam Co, a remote site in central Tibetan Plateau, Atmos. Res., 92, 42-48, 2009.

Cox, S. J., Stackhouse Jr., P. W., Gupta, S. K., Mikovitz, J. C., Zhang, T. P., Hinkelman, L. M., Wild, M., and Ohmura, A.: The NASA/GEWEX Surface Radiation Budget Project: Overview and analysis, paper presented at 12th Conference on Atmospheric Radiation, Am. Meteorol. Soc., Madison, Wis., 2006.

Demuth, H., Beale, M., and Hagan, M.: Neural Network Toolbox 6 User Guide, 2008.

Dutton, E. G., Michalsky, J. J., Stoffel, T., Forgan, B. W., Hickey, J., Nelson, D. W., Alberta, T. L., and Reda, I.: Measurement of broadband diffuse solar irradiance using current commercial instrumentation with a correction for thermal offset errors, J. Atmos. Ocean. Tech., 18, 297-314, 2001.

Geiger, M., Diabate, L., Menard, L., and Wald, L.: A Web service for controlling the quality of measurements of global solar irradiation, Sol. Energy, 73, 475-480, 2002.

Gilgen, H., Wild, M., and Ohmura, A.: Means and trends of shortwave irradiance at the surface estimated from GEBA, J. Climate, 11, 2042-2061, 1998.

Gilgen, H., Roesch, A. Wild, M., and Ohmura, A.: Decadal changes of shortwave irradiance at the surface in the period 1960 to 2000 estimated from Global Energy Balance Archive, J. Geophys. Res., 114, D00D08, doi:10.1029/2008JD011383,2009.

Gueymard, C. A.: Direct solar transmittance and irradiance predictions with broadband models. Part I. Detailed theoretical performance assessment, Sol. Energy, 74, 355-379, 2003a.

Gueymard, C. A.: Direct solar transmittance and irradiance predic- 
tions with broadband models. Part II. Validation with highquality measurements, Sol. Energy, 74, 381-395, 2003 b.

Jiang, Y. N.: Computation of monthly mean daily global solar radiation in China using artificial neural networks and comparison with other empirical models, Energy, 34, 1276-1283, 2009.

Kato, S., Ackerman, T. P., Clothiaux, E. E., Mather, J. H., Mace, G. R., Wesley, M., Murcray, F., and Michalsky, J.: Uncertainties in modeled and measured clear-sky surface shortwave irradiances, J. Geophys. Res., 102D, 25881-25898, 1997.

Liang, F. and Xia, X. A.: Long-term trends in solar radiation and the associated climatic factors over China for 1961-2000, Ann. Geophys., 23, 2425-2432, doi:10.5194/angeo-23-2425-2005, 2005.

Liepert, B. G.: Observed reductions of surface solar radiation at sites in the United States and worldwide from 1961 to 1990 , Geophys. Res. Lett., 29(10), 1421, doi:10.1029/2002GL014910, 2002.

Liepert, B. G. and Kukla, G. J.: Declines in global solar radiation with increased horizontal visibility in Germany between 1964 and 1990, J. Climate, 10, 2391- 2401, 1997.

Madkour, M. A., Metwally, M. E., and Hamed, A. B.: Comparative study on different models for estimation of direct normal irradiance (DNI) over Egypt atmosphere, Renew. Energy, 31, 361382,2006

Mubiru, J. and Banda, E. J. K. B.: Estimation of monthly average daily global solar irradiation using artificial neural networks, Sol. Energy 82, 181-187, 2008.

Norris, J. R. and Wild, M.: Trends in aerosol radiative effects over Europe inferred from observed cloud cover, solar "dimming," and solar "brightening", J. Geophys. Res., 112, D08214, doi:10.1029/2006JD007794, 2007.

Norris, J. R. and Wild, M.: Trends in aerosol radiative effects over China and Japan inferred from observed cloud cover, solar "dimming," and solar "brightening", J. Geophys. Res., 114, D00D15, doi:10.1029/2008JD011378, 2009.

Paulescu, M. and Schlett, Z.: A simplified but accurate spectral solar irradiance model, Theor. Appl. Climatol., 75, 203-212, 2003.

Paulescu, M. and Schlett, Z.: Performance assessment of global solar irradiation models under Romanian climate, Renew. Energy, 29, 767-777, 2004.

Pinker, R. T., Zhang, B., and Dutton, E. G.: Do satellites detect trends in surface solar radiation?, Science, 308, 850-854, 2005.

Qian,Y., Wang, W., Leung, L. R., and Kaiser, D. P.: Variability of solar radiation under cloud-free skies in China: the role of aerosols, Geophys. Res. Lett., 34, L12804, doi:10.1029/2006GL028800, 2007.

Ramanathan, V., Crutzen, P. J., Kiehl, J. T., and Rosenfeld, D.: Aerosols, climate, and the hydrological cycle, Science, 294, 2119-2124, 2001.

Shi, G. Y., Hayasaka, T., Ohmura, A., Chen, Z. H., Wang, B., Zhao, J. Q., Che, H. Z., and $\mathrm{Xu}$, L.: Data quality assessment and the long-term trend of ground solar radiation in China, J. Appl. Meteorol. Climatol., 47, 1006-1016, doi:10.1175/2007JAMC1493.1, 2008.

Stanhill, G.: Estimation of direct solar beam irradiance from measurements of the duration of bright sunshine, Int. J. Climatol., 18, 347-354, 1998

Stanhill, G. and Ianetz, A.: Long-term trends in and the spatial variation of global irradiance in Israel, Tellus B, 49, 112-122, 1997.

Stanhill, G. and Kalma, J. D.: Solar dimming and urban heating in
Hong Kong, Int. J. Climatol., 15, 933-941, 1995.

Tang, W. J., Yang, K., He, J., and Qin, J.: Quality control and estimation of global solar radiation in China, Sol. Energy, 84, 466475, 2010.

Tych, W., Pedegral, D. J., Young, P. C., and Davies, J.: An unobserved component model for multi-rate forecasting of telephone call demand: the design of a forecasting support system, Int. J. Forecasting, 18, 673-695, 2002.

Tymvios, F. S., Jacovides, C. P., Michaelides, S. C., and Scouteli, C.: Comparative study of Angström's and artificial neural networks' methodologies in estimating global solar radiation, Sol. Energy, 78, 752-762, 2006.

Wang, K. C., Dickinson, R. E., and Liang, S. L.: Clear sky visibility has decreased over land globally from 1973 to 2007, Science, 323, 1468-1470, 2009.

Wigley, T. M. L.: Appendix A: Statistical Issues Regarding Trends, in: Temperature Trends in the Lower Atmosphere: Steps for Understanding and Reconciling Differences, edited by: Karl, T. R., Hassol, S. J., Miller, C. D., and Murray, W. L., (A Report by the Climate Change Science Program and the Subcommittee on Global Change Research), Washington, DC, 129-139, 2006.

Wild, M., Gilgen, H., and Roesch, A.: From dimming to brightening: Decadal changes in solar radiation at earth's surface, Science, 308, 847-850, doi:10.1126/science.1103215, 2005.

Wild, M., Trüssel, B., Ohmura, A., Ohmura, A., Long, C. N., König-Langlo, K., Dutton, E. G., and Tsvetkov, A.: Global dimming and brightening: An update beyond 2000, J. Geophys. Res., 114, D00D13, doi:10.1029/2008JD011382, 2009a.

Wild, M.: Global dimming and brightening: A review, J. Geophys Res., 114, D00D16, doi:10.1029/2008JD011470, 2009b.

Xia, X. A., Wang, P. C., Chen, H. B., and Liang, F.: Analysis of downwelling surface solar radiation in China from National Center for Environmental Prediction reanalysis, satellite estimates, and surface observations, J. Geophys. Res., 111, D09103, doi:10.1029/2005JD006405, 2006.

Yang, K. and Koike, T.: A general model to estimate hourly and daily solar radiation for hydrological studies, Water Resour. Res., 41, W10403, doi:10.1029/2005WR003976, 2005.

Yang, K., Huang, G. W., and Tamai, N.: A hybrid model for estimating global solar radiation, Sol. Energy, 70, 13-22, 2001.

Yang, K., Koike, T., and Ye, B.: Improving estimation of hourly, daily, and monthly solar radiation by importing global data sets, Agric. Forest. Meteorol., 137, 43-55, 2006.

Yang, Y., Wang, D., Lv, W. H., Mo, Y. Q., and Ding, L.: Solar radiation standard and its values transfer system in China, available at: http://www.knmi.nl/samenw/geoss/wmo/TECO2008/ IOM-96-TECO2008/P1(52)_Yang_China.pdf (last access: July, 2010), 2008

Ye, J. S., Li, F. M., Sun, G. J., and Guo, A. H.: Solar dimming and its impact on estimating solar radiation from diurnal temperature range in China, 1961-2007, Theor. Appl. Climatol., 101, 137142,2010

Young, P., Pedegral, D. J., and Tych, W.: Dynamic Harmonic Regression, J. Forecasting, 18, 369-394, 1999.

Zhang, Y. L., Qin, B. Q., and Chen, W. M.: Analysis of 40 year records of solar radiation data in Shanghai, Nanjing and Hangzhou in eastern China, Theor. Appl. Climatol., 78, 217-227, 2004. 